\title{
Effect of starch-based edible coating application on potato chips characteristic from tubers and flour of potato variety Granola
}

\author{
"Wibowo, C., Erminawati, Wicaksono, R. and Haryanti, P. \\ Department of Food Science and Technology, Faculty of Agriculture, Jenderal Soedirman University, Jl. \\ Dr. Soeparno 61 Purwokerto 53123 Central Java Indonesia
}

\section{Article history: \\ May 2020 2020 \\ Keywords: \\ Chips, \\ Edible coating, \\ Potato, \\ Quality}

Received: 26 April 2020

Received in revised form: 20

Accepted: 31 May 2020

Available Online: 16 July

DOI:

https://doi.org/10.26656/fr.2017.4(6).190

\begin{abstract}
Edible coating made from starch contributes to reducing oil uptake during processing. This research aimed to examine the effects of the edible coating application on the characteristics of potato chips prepared from the fresh tuber (PCT) and potato flour (PCF). The raw material for chipping was potato variety Granola. The edible coating was produced from sago starch, arrowroot starch, and tapioca. Edible coating from alginate was also examined. The coating was applied on the potato slices before frying. The parameters observed in this study were fat and moisture content, color parameter, and sensory properties that include crunchiness, a taste of potato, and preference. The results showed that the edible coating made from sago starch, arrowroot starch, and alginate reduced oil absorption of chips $3.90 \%, 8.29 \%$, and $14.56 \%$, respectively. There was no effect of edible coating found on the moisture content of chips. The L-, a-, and b-value indicate that the coated chips did not have a bright yellow color. All of the treated chips had L-value lower than 55. Most of the sensory properties of coated chips had a low hedonic score (less than 3 ) that were not preferred by the panelists. Whereas crunchiness and taste of chips made from the flour were still accepted by the panelists, the hedonic score was higher than 3 .
\end{abstract}

\section{Introduction}

The edible coating is applied to either fresh or processed food to maintain the quality and prolong the shelf-life. Several types of substances can be used for the main ingredients of edible coating, including hydrocolloid, proteins, lipids, and polysaccharides. Starch is a polysaccharide that has a good effect as an ingredient for an edible coating that contributes to the food's quality (Garmakhany et al., 2012; Fakhouri et al., 2015; Angor, 2016). Edible coating useful for reducing weight loss, maintaining vitamin $\mathrm{C}$ level, delaying decay, and maintaining the sensory quality of fresh fruits (Misir et al., 2014; Fakhouri et al., 2015; Azeredo and Waldron, 2016). Moreover, the application of edible coating contributes also to reducing oil absorption in fried processed products such as fried peas or French fries (Garmakhany et al., 2012; Zhu et al., 2015).

Food products with low-fat content become an important consideration for the producer because of increasing consumers' awareness of selecting the food. In addition to the food's composition, temperature, and duration of frying, pre-treatment before frying and draining after frying influence the total oil absorbed by the food. Previous research reported that starch-based edible coating contributes to reducing oil uptake of fried potato during frying (Garmakhany et al., 2012; Angor, 2016). Starch is abundantly available in tubers. Several tubers that are widely cultivated in Indonesia are taro (Colocasia esculenta L. Schoott), elephant foot yam (Amorphophallus companulatus), cassava (Manihot esculenta), canna (Canna edulis Ker.), yam (Dioscorea hispida), sweet potato (Ipomoea batatas), porang (Amorphophallus muelleri Blume), sago (Metroxylon $s a g u$ ), and arrowroot (Maranta arundinacea). These tubers are potential sources for producing starch as the main material of the edible coating.

The quality of fried food mainly depends on the frying process. Potato chips and French fries are popular food products that contain high fat content due to the absorption of oil during frying. In Indonesia, the consumption of french-fries, and potato chips increases year by year because of the high demand. Therefore, the amount of imported processing potato is growing. The raw material of processing potato mostly is imported 
because the dominant potato tuber in Indonesia is a variety of Granola (Pusat Data dan Sistem Informasi Pertaninan - Kementerian Pertanian, 2017). Potato tuber variety Granola is suitable as table potato and not appropriate for processing one due to the high content of moisture and reducing sugar. Thus, the tubers will produce a soggy, oily, and dark brown color of chips (Wibowo et al., 2004; Bafdal and Wibowo, 2019; Europotato.org, 2020). Abbasi et al. (2019) suggested that the tuber with high dry matter content, low fat, and reducing sugar content as a raw material of potato chips to produce crunchy, gold-brown color and preferred by the consumers. Alternatives for using potato variety Granola for chipping production are applying pretreatments (blanching, pre-drying, coating, immersing in $\mathrm{CaCl}_{2}$ ) or grind it into powder form then mixing with other flours. Processing the tuber into potato flour will ensure availability throughout the year because of its shelf-life.

To improve the quality of potato chips, several efforts have been conducted to reduce oil uptake during frying such as application of single and multi-layer coating (Garmakhany et al., 2012), applying an edible coating from several sources: chitosan (Elsabee and Abdou, 2013), pectin (Valdes et al., 2015), starch and protein (Azeredo and Waldron, 2016), gelatin (Fakhouri et al., 2015), alginate (Souza et al., 2015), maltodextrin, acacia gum and carboxymethyl cellulose (Wibowo et al., 2018). In the present research, utilization of local tubers in Indonesia was proposed as an alternative main ingredient for producing edible coating. Information regarding the utilization of potato variety Granola as the main material for chips is limited. Therefore, this research is aimed to examine the use edible coating on potato chips made from the potato tuber and potato flour.

\section{Material and methods}

The tubers used in this study were fresh potato tuber variety Granola obtained from Dieng Plateau in Central Java (one of the main producers of potato tubers in Indonesia), potato flour from its tuber was produced according to Wibowo et al. (2018). Other materials, such as wheat flour, rice flour, baking soda, salt, and cooking oil, are commercial products that easily accessible in the market. The main ingredients used as edible coatings consist of alginate, sago starch, arrowroot starch, and tapioca starch were obtained from the grocery store. The existing edible coating that has been widely used, alginate as a coating material was also prepared.

\subsection{Potato chips from the tubers (PCT)}

Potato used for chips production had a diameter of 40-60 $\mathrm{mm}$. The tubers were washed and peeled, followed by slicing the tubers with the potato slicer, the thickness of the slices were $2 \mathrm{~mm}$. The potato slices were rinsed by tap water and dried with a paper towel. Afterwards, the slices were immersed in the edible coating for about $5 \mathrm{~s}$. The coated slices were put on the wire screen with blowing the air to the surface. The frying process was conducted by an electrical fryer at $160^{\circ} \mathrm{C}$ (Oxone Deep Fryer OX-989, Indonesia) with palm oil. The fried product was drained on the wire screen and paper towel then kept in a plastic container with silica gel.

\subsection{Potato chips produced from potato flour (PCF)}

The composition of the dough consisted of potato flour: wheat flour: rice flour at 60:20:20. This recommended mixture was obtained from the previous research (Wibowo et al., 2018). Salt and baking soda were added to the dough to improve the crunchiness and give a taste of the chips. Kneading was applied to the mixture for about 20 mins and the addition of water at the same time. The dough was treated by pasta machine (Oxone OX 255AT, Indonesia) to have a homogenous thickness, $2 \mathrm{~mm}$. The sheet was cut by a round-shape mold with a $5 \mathrm{~cm}$ diameter. The round-shape pieces were immersed in the edible coating for about $5 \mathrm{~s}$ and then put on the wire screen. The air was blown to the pieces to support the drying process. The pieces were fried in the electrical fryer by deep-frying method at $160^{\circ} \mathrm{C}$ (Oxone Deep Fryer OX-989, Indonesia) with palm oil. After draining the oil, the chips were kept in a plastic container with silica gel.

\subsection{Experimental design}

The design of this study was experimental using Randomized Block Design (RBD). Each treatment was performed three times. The treatment observed in this study consisted of two factors that were the type of raw materials for potato chips $(\mathrm{K})$ consisting of potato flour from variety Granola (K1) and fresh tubers variety Granola (K2). The second factor was the main material for edible coating (E) consisting of: without edible coating (E0), alginate (E1), sago starch (E2), arrowroot starch (E3) and tapioca (E4). The coating was prepared separately by heating $4 \mathrm{~g}$ of the material in $100 \mathrm{~mL}$ water at $70^{\circ} \mathrm{C}$ for 10 mins with continuous stirring.

\subsection{Evaluation of potato chips' characteristic}

The parameters examined in this study include fat and moisture content, color parameters, and sensory evaluation. Fat and moisture content were measured according to methods of AOAC (AOAC, 2005). Color parameters were evaluated by using Colorimeter (Minolta CR-10, Japan) according to Abbasi et al. (2015). A sensory evaluation which includes 
crunchiness, a typical taste of potato, and preference of potato chips was conducted according to Angor (2016) with a few modifications. A sensory panel, which consisted of thirty-four untrained panelists, was required to assess the product. Before conducting the evaluation, they were familiarized with the sensory test procedure and scoring for the assessment. They were asked to present their response to the four-point scale of the hedonic test. Sensory properties evaluated were crunchiness $(1=$ "not crunchy" to $4=$ "very crunchy" $)$, a typical taste of potato $(1=$ "not detected" to $4=$ "very intense" $)$ and preference ( $1=$ "do not like" to $4=$ "very like").

\subsection{Data analysis}

The data obtained from this study were analyzed by variance analysis (F test) and if the result of the analysis showed a significant effect, then continued with Duncan's Multiple Rank Test (DMRT). Data obtained from the analysis of sensory were analyzed by the Kendall correlation test and to find out the differences, a Wilcoxon signed-rank test was applied.

\section{Result and discussion}

\subsection{Fat Content}

Fried food products mostly have high fat content as a result of direct contact of food with cooking oil during frying. The frying process is an important activity that determines the quality of final products, including the color and texture of the chips. The effect of various types of edible coating materials on fat content can be seen in Figure 1. The results present that different edible coating material had a significant effect on the fat content of potato chips (PCF and PCT). This is because the surface of the chips is coated with edible coating making it difficult for oil to permeate into the products. In the present research, edible coating from alginate performed better than others by $14.56 \%$ lower than control on fat content. Alginates are extracted from brown seaweeds of the Phaeophyceae that impervious to oil and grease (Khan et al., 2013). This is one of the reasons using alginate for comparison of these starch-based edible coating produced from the local resources.

Edible coating prepared from the sago and arrowroot starch results in potato chips with $3.90 \%$ and $8.29 \%$ lower of fat content than control. This reduction is lower than those from alginate, it could be the less concentration applied to the chips. The concentration of coating applied to fried products plays an important role in reducing oil uptake during frying as reported by Garmakhany et al. (2012), they found that the higher concentration coating of guar, $\mathrm{CMC}$, xanthan, and mixed gum reduce the fat content of the fried potato. The coating on the surface of the ingredients before the frying process will hamper oil absorption. Starch will form a thin layer on the surface of the chips which will prevent evaporation of water during frying, resulting in minimum fat absorbed in chips (Mellema, 2003; Angor, 2016). However, the fat content of chips with tapioca coating does not significantly different from control. Referring to the previous research that uses the carboxymethyl Cellulose (CMC) as a coating for potato pellet chips reported that higher concentration of $\mathrm{CMC}$ applied gives a bigger reduction on oil absorption during frying (Angor, 2016). Therefore, the concentration of tapioca used in this research could be not high enough to perform on minimizing oil absorption. Garmakhany et al. (2012) presented that coating contributes significantly to reducing the fat content of potato French fries at an appropriate concentration of the coating.

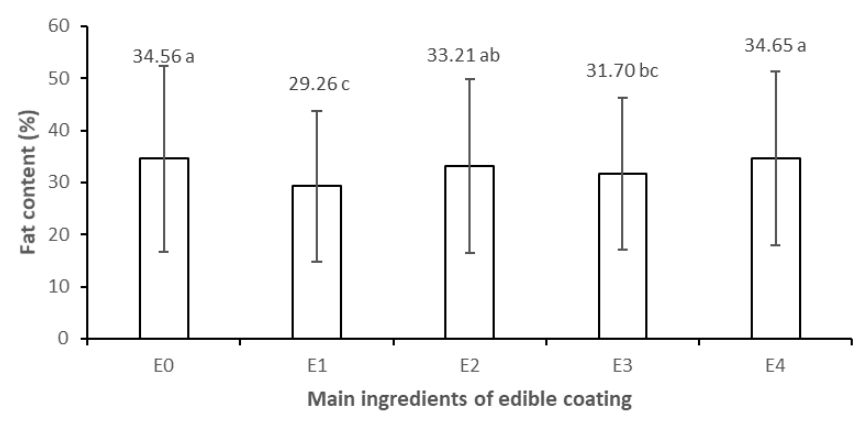

Figure 1. The effect of edible coating on the fat content of potato chips. E0: control, E1: Alginate, E2: Sago starch, E3: Arrowroot starch, E4: Tapioca. Bars with the different letters are significantly different at 0.05 .

\subsection{Moisture content}

The initial moisture content in each food product varies. Potato tuber variety Granola has a high moisture content, about $80 \%$ (Wibowo et al., 2004). The moisture content of raw material will influence the moisture content of the final product. The effect of types of raw materials for chips production on moisture content is presented in Figure 2. The moisture content of PCF is relatively higher than the PCT. It could be due to the addition of water during the preparation of the dough that increases the moisture content of the chips. Moreover, the slices of chips were dipped in a solution of edible coating that contains high moisture content before frying. PCF are a mixture with other flours which consists of starch and protein that binds water so that water is difficult to discharge when frying. The previous research which explains that water is usually bound to the surface or to the layers around hydrophilic molecules, such as proteins, carbohydrates, pectin, and starches that are bound through intermolecular hydrogen bonds (Angor, 2016). In this research, there is no effect of edible coating on moisture content that ranges 
between $3.36 \%$ to $4.67 \%$. It could be as a result of the barrier properties of the coating agents that inhibit moisture removal during frying. Angor (2016) also presented that using $\mathrm{CMC}$ at $2 \%$ concentration results in no difference with the control, whereas, the application of $\mathrm{CMC}$ at $6 \%$ and higher produces the chips with a significant difference than control on moisture content. Meanwhile, Garmakhany et al. (2012) reported that coated French fries with pectin, CMC, guar, and xanthan produce higher moisture content than the control.

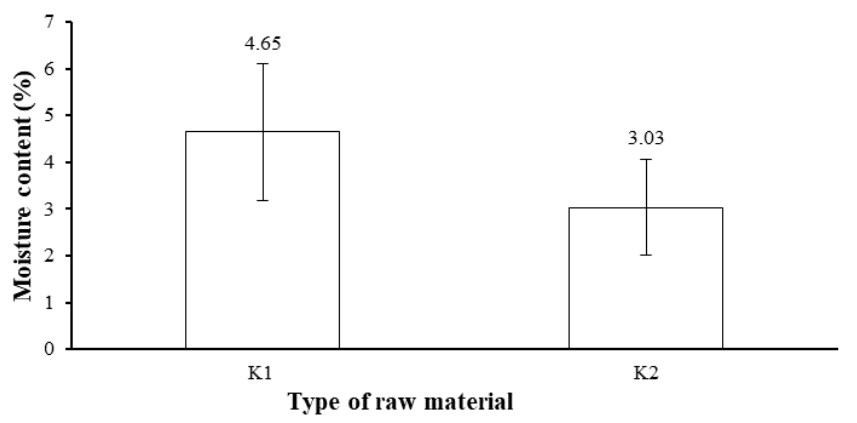

Figure 2. The effect of the raw material of potato chips on moisture content. K1: Potato flour, K2: Potato tubers

\subsection{Color}

The preferred color of potato chips is golden-yellow one, the important factor that determines the color is frying. Therefore, the frying process in chips production is a critical point. In this research, the brightness was observed, the higher value (L-value) the brighter is the chips. The highest value is 100 and the lowest one is 0 , which means very dark/black. In this research, the Lvalue is lower than 55, whereas, the report from the prior researchers the L-value is more than 58 (Abbasi et al., 2015). It means the brightness of the chips in the present research is less bright than those from their research.

The brightness of potato chips produced is low, it causes by the possibility of a browning reaction during preparation on producing the flour and inappropriate

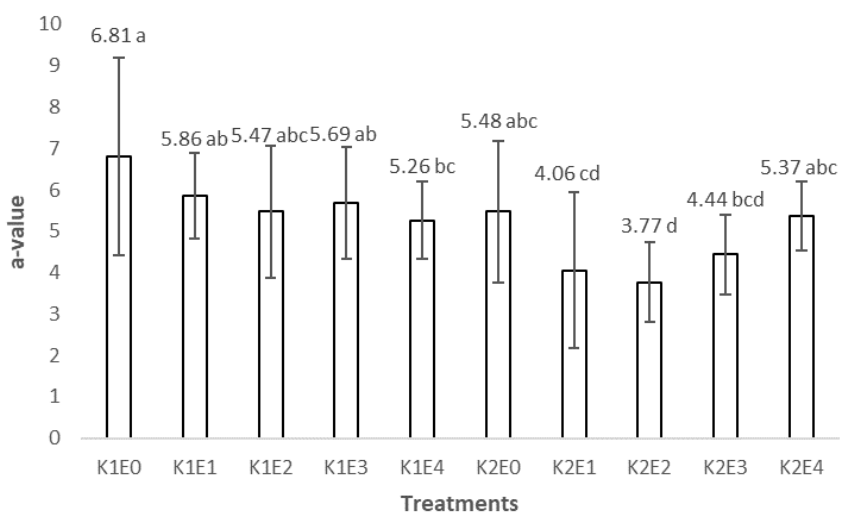

Figure $3 \mathrm{~b}$. The effect treatments on a-value. K1: Potato flour, K2: Potato tubers, E0: control, E1: Alginate, E2: Sago starch, E3: Arrowroot starch, E4: Tapioca. Bars with the different letters are significantly different at 0.05 . concentration of edible coating applied to the chips. This result is supported by the previous report (Mu and Sun, 2017) who reported that the higher concentration of the edible coating applied will produce lower L-value. The inappropriate concentration of edible coating will produce an opaque cover on the surface of the slices (Abbasi et al., 2015). The result of determining the L-, a, and b-value are presented in Figure $3 a, 3 b$, and $3 c$. In this research, most coated chips do not perform better than control. In contrast, Hua et al. (2015) presented that the application of edible coating improves the a- and bvalue, therefore the chips' color tends to yellow to bright brown. Moreover, comprehensive research on evaluating the color properties of potato flour as affected by several treatments during preparation was conducted previously. They reported that duration and temperature of blanching, drying plays an important role in determining the L-, a-, and b-value (Mu and Sun, 2017). Also, they informed that the concentration of ascorbic acid, citric acid, and calcium chloride also influences the color properties of potato flour ( $\mathrm{Mu}$ and Sun, 2017). In the present research, there was an addition of citric acid to prevent browning enzymes after slicing, with a concentration of $0.75 \%$, during the production of potato flour. According to Mu and Sun (2017), it is necessary to

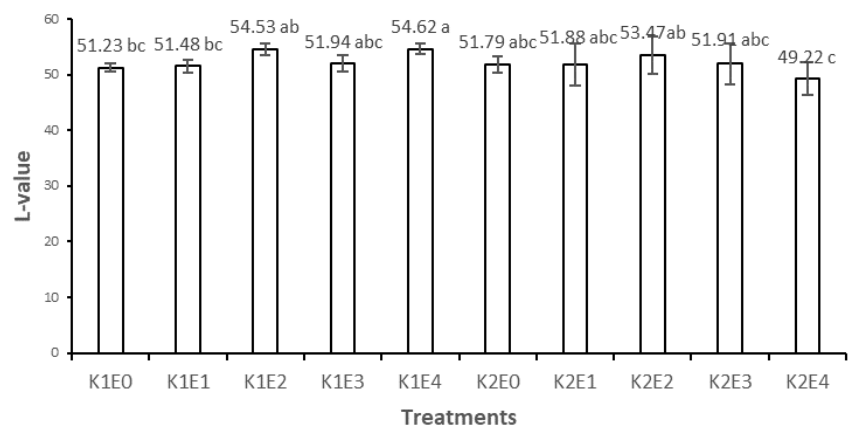

Figure 3a. The effect treatments on L-value. K1: Potato flour, K2: Potato tubers, E0: control, E1: Alginate, E2: Sago starch, E3: Arrowroot starch, E4: Tapioca. Bars with the different letters are significantly different at 0.05 .

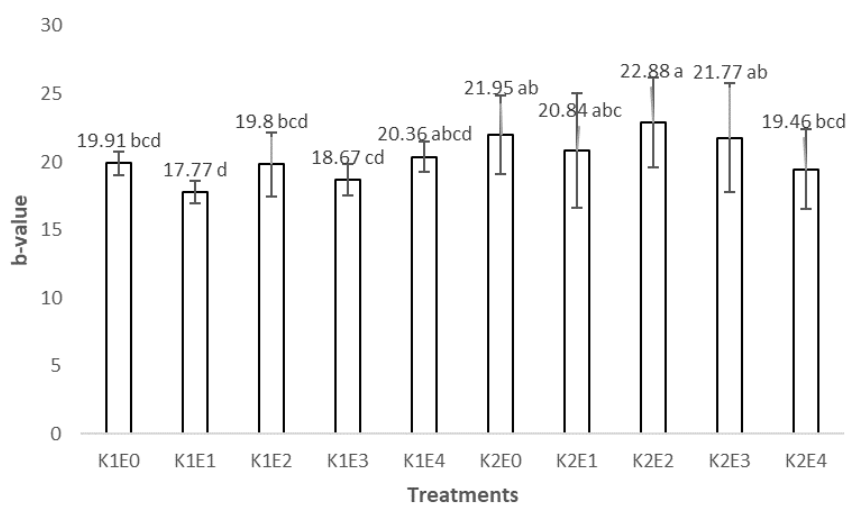

Figure 3c. The effect treatments on b-value. K1: Potato flour, K2: Potato tubers, E0: control, E1: Alginate, E2: Sago starch, E3: Arrowroot starch, E4: Tapioca. Bars with the different letters are significantly different at 0.05 . 
soak the potato tubers with $1.2 \%$ citric acid because the immersing of slices in this solution will produce a better color of produced chips. In this research, a concentration of $1.2 \%$ of citric acid concentration cannot be applied to potato flour because too acidic taste that leads to low acceptance of the consumers. Therefore, the frying process and initial color of raw materials will contribute to the chips' color.

\subsection{Sensory properties}

\subsubsection{Crunchiness}

The crunchiness of potato chips is developed during frying due to the hardening of the surface. Figure $4 \mathrm{a}$ shows the crunchiness score of potato chips. In the present research, the coated chips (PCF and PCT) do not different compare to control. Coating applications influence the starch gelatinization and retrogradation that could affect crust forming on the surface of chips (Hua et al., 2015). Previous research presented that an appropriate concentration of edible coating applied on the potato chips increases the crunchiness because of the effect of gelatinization. However, too high concentration of edible coating results in an excessive moisture content in the chips that lead to a decrease in the crunchiness (Abbasi et al., 2015). The PCF is expected better performance on the crunchiness property compared to PCT because there was additional of other flours. However, the results did not indicate that PCF crunchier than PCT. The raw material of chips from dough contains low moisture content but during preparation, there is an additional of water that increases the moisture content of the dough. The prior research reported that treatments during the preparation of producing potato flour influence the properties of the final product, for example, drying that will reduce moisture content, damaged starch content, particle size, and color $(\mathrm{Mu}$ and Sun, 2017). The lower the moisture content of the product, the crunchier the product will be. Therefore, high dry matter content is a necessary requirement for producing crunchy texture of the chips.

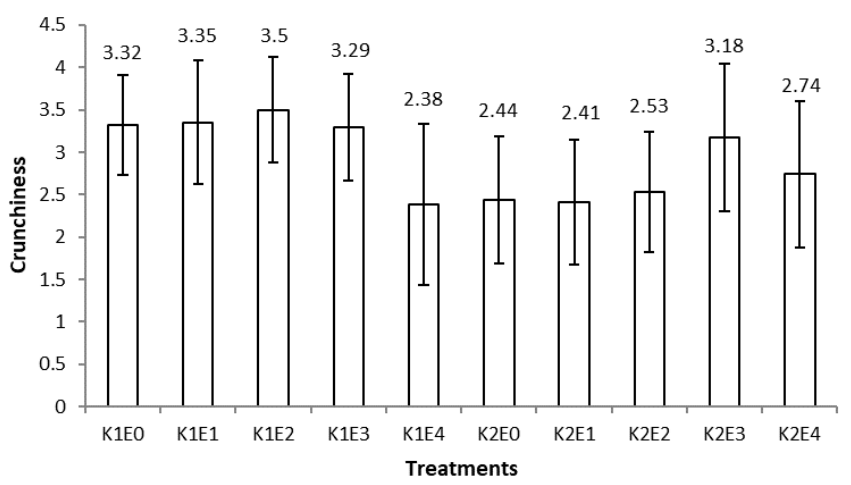

Figure 4a. The effect of treatments on chips' crunchiness. K1: Potato flour, K2: Potato tubers, E0: control, E1: Alginate, E2: Sago starch, E3: Arrowroot starch, E4: Tapioca. Bars with the different letters are significantly different at 0.05 .

\subsubsection{Taste}

Panelists rate the presence of the typical taste of potatoes found in both potato chips, PCF and PCT. Panelists' mean scores on the taste of potatoes are presented in Figure 4b. Figure $4 \mathrm{~b}$ shows that the average value ranged from 2.26 (moderate noticeable) to 3.26 (noticeable). This result shows that the addition of edible coating on the surface of slices or pieces of potato before frying has no negative effect because the panelists still recognize the taste of the potato. PCT had a pronounced taste of potatoes felt because there is no mixture of other ingredients. PCF were scored slightly lower because there is a mixture of other flours. Wheat flour and rice flour contribute to influencing the taste of potatoes. The mixture of ingredients overshadows the taste of potatoes on PCF. Moreover, there was an immersion of potato slices in $0.75 \%$ citric acid in the processing of potato flour that affected further reduces the taste of potatoes. Hua et al. (2015) reported that coating application on potato chips reduces hedonic score on chips' taste. Coating of chips causes a reduction of lipid-soluble flavor compounds in a fried product that generates different mouth feeling (Hua et al., 2015).

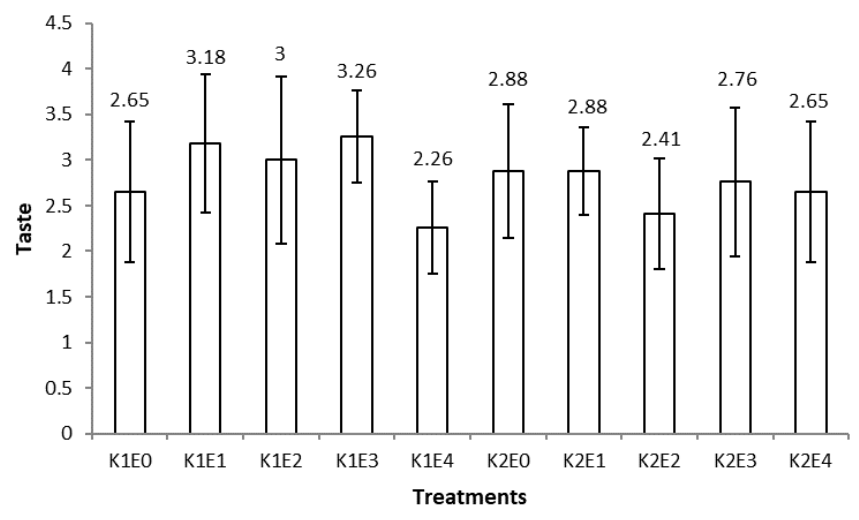

Figure $4 \mathrm{~b}$. The effect of treatments on chips' taste. K1: Potato flour, K2: Potato tubers, E0: control, E1: Alginate, E2: Sago starch, E3: Arrowroot starch, E4: Tapioca. Bars with the different letters are significantly different at 0.05 .

\subsubsection{Preference}

Preference is a response of panelists to the overall chips' properties. It determines whether a product will be well received or not by panelists. Panelists' mean scores on potato chips preference from each treatment are presented in Figure 4c. Figure 4c presents the panelists' preference mean scores of potato chips ranged from 2.15 (rather like) to 3.21 (like) and most of them are below 3. This result shows that the panelist does not like yet the treated chips by coating. The chips in this research (PCF and PCT) are not crunchy enough, the color tends to brown and acceptable taste. These properties are not expected by the panelist because potato chips should 
have a crunchy texture, golden-yellow color, and intense taste of potato. Hua et al. (2015) who conducted a sensory evaluation with 30 trained panelists reported that coating application on potato chips had a lower hedonic score on chips' preference than uncoated ones. They reported that coating influence chips during frying that resulting different color change, starch gelatinization and retrogradation process, forming a crust, and different mouth feeling. These changes on coated potato chips can be detected by the panelist, therefore, they prefer the uncoated chips than the coated ones. On the contrary, Angor (2016) presented that coating on potato pellet chips increases the hedonic score higher than control including color, taste, crunchiness, and preference.

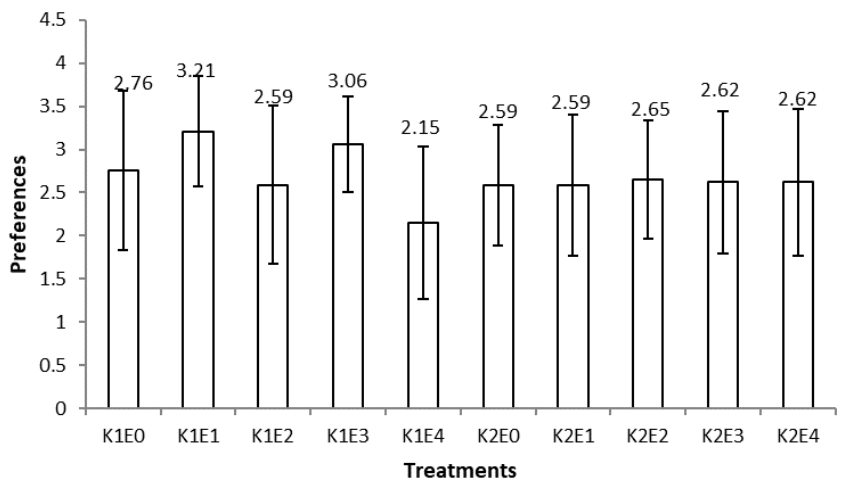

Figure 4c. The effect of treatments on chips' preference. K1: Potato flour, K2: Potato tubers, E0: control, E1: Alginate, E2: Sago starch, E3: Arrowroot starch, E4: Tapioca. Bars with the different letters are significantly different at 0.05 .

Summarizing the results of this research, to produce potato chips with desired color and crunchiness, it requires potato tubers with the high dry matter, low fats, and reducing sugar (Amjad et al., 2019). This requirement can not be fulfilled by the potato tuber variety Granola that cultivated in Indonesia. The result in this research showed that potato chips can be produced from the tuber variety Granola with additional treatments. Therefore, it is an opportunity for utilizing this variety as raw material for potato chips. However, additional pretreatments are required to improve the appropriateness of the characteristic. Producing potato chips from the flour is more promising because there is a possibility for mixing with other ingredients during processing for improving the chips' characteristics and nutrition content. The previous research reported that the modification on potato starch cause changes in its physicochemical characteristic and its digestibility. Therefore, it initiates the possibility of using potato starch as the main ingredient for chips production for further research (Heo et al., 2017; Won et al., 2017). Another reason for recommends the use of flour rather than tubers of potato variety Granola as a raw material of potato chips is the shelf life of the material. Potato flour which has low moisture content can be stored for a longer duration than the tubers. Moreover, the previous research showed that the storage of potato tubers at low temperature initiates the accumulation of reducing sugars. The high content of reducing sugar of tubers will produce potato chips with undesired color (Amjad et al., 2019).

\section{Conclusion}

The application of edible coating made of sago starch, arrowroot starch, and alginate can slightly reduce the oil absorption of PCT and PCF during frying. There is no effect found on the moisture content of all treated chips. The L-, a-, and b-value indicate that the coated chips tends to have dark-yellow color. The sensory evaluation shows that the coated chips (PCT and PCF) need improvement on crunchiness and taste to be preferred by the panelists because the hedonic score obtained is still low. However, panelists still detect the typical taste of potato on coated chips. Therefore, the edible coating could be one of the alternatives for improving the quality of potato chips produced from the tuber variety Granola. However, further research is required to improve the sensory properties and examine the shelf life of the chips.

\section{Conflict of interest}

The authors declare no conflict of interest.

\section{Acknowledgment}

The authors are grateful to the Institute for Research and Community Services of Jenderal Soedirman University for supporting the research.

\section{References}

Abbasi, K.S., Masud, T., Ali, S., Mahmood, T., Hussain, A., Liaquat, M. and Jahangir, M. (2015). Quality of Potato Chips as Influenced by Aloe Vera Coating. Journal of Food and Nutrition Research, 3(3), 157161. https://doi.org/10.12691/jfnr-3-3-5

Abbasi, K.S., Qayyum, A., Mehmood, A., Mahmood, T., Khan, S.U., Liaquat, M., Sohail, A. and Ahmad A. (2019). Analysis of selective potato varieties and their functional assessment. Food Science and Technology, 39(2), 308-314. https://doi.org/10.1590/ fst. 26217

Amjad, A., Javed, M.S., Hameed, A., Hussain, M. and Ismail, A. (2019). Changes in sugar content and invertase activity during low-temperature storage of various chipping potato cultivars. Food Science and Technology, 40(2), 340-345. https://doi.org/10.1590/ fst.00219

Angor, M.M. (2016). Reducing Fat Content of Fried 
Potato Pellet Chips Using Carboxymethyl Cellulose and Soy Protein Isolate Solutions as Coating Films. Journal of Agricultural Science, 8(3), 162-169. https://doi.org/10.5539/jas.v8n3p162

AOAC. (2005). Official Methods of Analysis. Association of Analytical Chemists. $15^{\text {th }} \mathrm{Ed}$. Virginia, Arlington, USA: AOAC.

Azeredo, H.M.C. and Waldron, K.W. (2016). Crosslinking in Polysaccharide and Protein Films and Coatings for Food Contact-A Review. Trends in Food Science and Technology, 52, 109-122. https:// doi.org/10.1016/j.tifs.2016.04.008

Bafdal, N. and Wibowo, C. (2019). Impact of Interval Irrigation on Amino Acids Composition and Minerals Content of Potato Tubers Granola and Eigenheimer Cultivars. International Journal on Advanced Science, Engineering and Information Technology, 9(3), 804-809. https://doi.org/10.18517/ ijaseit.9.3.9140

Elsabee, M.Z. and Abdou, E.S. (2013). Chitosan Based on Edible Films and Coatings: A Review. Materials Science and Engineering, 33(4), 1819-1841. https:// doi.org/10.1016/j.msec.2013.01.010

Europotato.org (2020). Granola. Retrieved on May $15^{\text {th }}$, 2020 from Europotato website: https:// www.europotato.org/ varieties/view/Granola-E.

Fakhouri, F.M., Martellia, S.M., Caonc, T., Velascod, J.I. and Mei, L.H. (2015). Edible films and coatings based on starch/gelatin: Film Properties and Effect of Coatings on Quality of Refrigerated Red Crimson Grapes. Postharvest Biology and Technology, 109, 57-64. https://doi.org/10.1016/ j.postharvbio.2015.05.015

Garmakhany, A.D., Mirzaei, H.O., Maghsudlo, Y., Kashaninejad, M. and Jafari, S.M. (2012). Production of low-fat french-fries with single and multi-layer hydrocolloid coatings. Journal of Food Science and Technology, 51(7), 1334-1341. https:// doi.org/10.1007/s13197-012-0660-9

Heo, H., Lee, Y.K. and Chang, Y.H. (2017). Effect of cross-linking on physicochemical and in vitro digestibility properties of potato starch. Emirates Journal of Food and Agriculture, 29(6), 463-469. https://doi.org/10.9755/ejfa.2017-01-237

Hua, X., Wang, K., Yang, R. and Yang, H. (2015). Edible coatings from sunflower head pectin to reduce lipid uptake in fried potato chips. LWT-Food Science and Technology, 62(2), 1220-1225. https:// doi.org/10.1016/j.lwt.2015.02.010

Khan, M.I., Adrees, M.N., Tariq, M.R. and Sohaib, M. (2013). Application of edible coating for improving meat quality: A review. Pakistan Journal of Food Sciences, 23(2), 71-79.
Mellema, M. (2003). Mechanism and Reduction of Fat Uptake in Deep-fat Fried Foods. Trends in Food Science and Technology, 14(9), 364-373. https:// doi.org/10.1016/S0924-2244(03)00050-5

Misir, J., Brishti, F.H. and Hoque, M.M. (2014). Aloe vera gel as a Novel Edible Coating for Fresh Fruits: A Review. American Journal of Food Science and Technology, 2(3), 93-97. https://doi.org/10.12691/ ajfst-2-3-3

$\mathrm{Mu}, \mathrm{T}$. and Sun, H. (2017). Progress in Research and Development of Potato Staple Food Processing Technology. Journal of Applied Glycoscience, 64(3), 51-64. https://doi.org/10.5458/jag.jag.JAG2016_017

Pusat Data dan Sistem Informasi Pertaninan Kementerian Pertanian. (2017). Buletin Triwulanan Konsumsi Pangan. Vol. 8, No. 2. Indonesia: Pusat Data dan Sistem Informasi Pertaninan Kementerian Pertanian. [In Bahasa Indonesia].

Souza, M.P., Vaz, A.F., Cerqueira, M.A., Texeira, J.A., Vicente, A. and Carneiro-da-Cunha, M.G. (2015). Effect of an Edible Nanomultilayer Coating By Electrostatic Self-Assembly On the Shelf Life of Fresh-Cut Mangoes. Food Bioprocess Technology, 8, 647-654. https://doi.org/10.1007/s11947-014-1436 $-1$

Valdes, A., Burgos, N., Jiménez, A. and Garrigós, M. (2015). Natural Pectin Polysaccharides as Edible Coatings. Coatings, 5(4), 865-886. https:// doi.org/10.3390/coatings5040865

Wibowo, C., Pawelzik, E., Delgado, E. and Nurpilihan. (2004). Strengthening Food Security Program by Utilization of Medium Altitudes Land on Potato Cultivation. Journal of Agriculture and Rural Development in the Tropics and Subtropics, 80, 5360.

Wibowo, C., Wicaksono, R. and Erminawati. (2018). Effect of Edible Coating on Quality of Chips from Potato Variety Granola. International Journal on Advanced Science, Engineering and Information Technology, 8(5), 2099-2105. https:// doi.org/10.18517/ijaseit.8.5.4331

Won, C., Jin, Y.I., Chang, D.C., Kim, M., Lee. Y., Ganesan, P., Lee, Y.K. and Chang, Y.H. (2017). Rheological, pasting, thermal and retrogradation properties of octenyl succinic anhydride modified potato starch. Food Science and Technology, 37(2), 321-327. https://doi.org/10.1590/1678-457x.23616

Zhu Y.Y., Zhang, M. and Wang, Y.Q. (2015). Vacuum frying of peas: effect of coating and pre-drying. Journal of Food Science and Technology, 52(5), 3105-3110. https://doi.org/10.1007/s13197-014-1314 $-\mathrm{x}$ 